\title{
An objective assessment of the variability in number of drops per bottle of glaucoma medication
}

\author{
Daniel B. Moore ${ }^{1 *}$, Judy Beck ${ }^{1}$ and Richard J Kryscio²
}

\begin{abstract}
Background: The purpose of this study is to evaluate the number of eyedrops available per bottle of a variety of commonly prescribed glaucoma medications.

Methods: Six bottles of each glaucoma medication were tested: three each in the vertical and horizontal orientations. Bottles were housed in a customized force gauge apparatus designed to mimic ballpoint fingertip contact with a bottle. At a standard rate, all drops were expressed from each bottle and counted with an automated drop counter. Simultaneously, bottle volume was measured and drop size and number were also estimated. The main outcome measures were: total number of drops, volume per bottle and drops per milliliter $(\mathrm{mL})$ of glaucoma medication.
\end{abstract}

Results: A total of 192 bottles from 32 bottle designs and manufacturers were tested. Twenty-two of the 32 bottle designs had a significantly different mean number of drops in the vertical and horizontal positions, with 10 designs have more drops dispensed in the horizontal orientation and 12 in the vertical orientation. Six of the 32 bottle designs had a significantly different mean total bottle volume in the vertical and horizontal positions, with all designs having greater volume in the vertical position. An adjusted ratio of mean number of drops/mean bottle volume demonstrated a range from $20.9 \mathrm{drops} / \mathrm{mL}$ to $40.8 \mathrm{drops} / \mathrm{mL}$.

Conclusions: There is significant variability in drops and volume available per bottle of glaucoma medication depending on both the bottle position and manufacturer. These data point to the need for circumspection in prescribing glaucoma medications and caution in evaluating therapeutic outcomes.

Keywords: Glaucoma, Pharmacology, Therapeutics, Eyedrop, Compliance, Bottle

\section{Background}

Although data demonstrate improved outcomes with lowered intraocular pressure from appropriate pharmacotherapy $[1,2]$, many patients with glaucoma struggle to adhere to their prescribed regimens. Several studies suggest patients comply with $70 \%$ or fewer of their glaucoma medications [3-5]. Many factors have been implicated [6], but difficulty instilling drops has garnered recent attention [7]. Proper eyedrop administration requires eye-hand coordination and dexterity, linking visual acuity with a steady hand and accurate

\footnotetext{
* Correspondence: daniel.b.moore@uky.edu

'Department of Ophthalmology and Visual Sciences, University of Kentucky,

740 S. Limestone, Lexington, KY 40536, USA

Full list of author information is available at the end of the article
}

proprioception [8]. Not surprisingly, videotape evidence demonstrated that glaucoma patient used an average of 1.4-1.8 drops when trying to instill a single eyedrop [9, 10]. A recent cross-sectional patient survey revealed that $25 \%$ of patients reported problems with early eyedrop bottle exhaustion and associated compliance with therapy. One-third of patients reported the reason for early bottle exhaustion was due to bottle related problems such as "more than one drop comes out" or "size of drops is too large". The latter complaint is supported by literature that demonstrates the volume of an eyedrop in an ophthalmic solution may vary from 25 to $70 \mu \mathrm{l}$ [11]. Given the normal tear film volume is $7 \mu \mathrm{l}$ and only capable of containing $30 \mu \mathrm{l}$ without overflow, a significant portion of an eyedrop is wasted [12]. These data suggest that a 
significant number of glaucoma patients run out of eyedrops prior to a scheduled prescription refill and that bottle related mechanics play a role [13].

Despite the importance of bottle design in proper use of topical therapeutics, there exists no standardization of manufacture in regards to drop instillation dynamics [14], and the only dosing requirement is to accurately label and package medication volume [15]. Being manufactured and sold on the basis of volume, eyedrops are distinct from most other forms of pharmacotherapy, which are prescribed with a discrete number of doses to guide dispensing and refill rates. While the minimum volume of medication consumers should anticipate per container of medication is available, this does not necessarily translate to number of applications, and without regulation, leads to the possibility of inconsistency in the number of drops of medicine available per bottle. Several previous studies evaluating a smaller number of medications in a non-standardized fashion have found significant variability in the number of drops between both brands of medication and position of the bottle [16-18]. As such, the current study was designed to further evaluate this possibility by objectively and systematically measuring the number of eyedrops in each bottle of many common glaucoma medications.

\section{Methods}

The number of eyedrops dispensed from various common glaucoma medications was measured. All medications were purchased at cost from the University of Kentucky Research Pharmacy and represented available regional brand and generic medications. A force gauge apparatus consisting of a Mecmesin M500E Motorised Tension and Compression Test Stand, Mecmesin $100 \mathrm{~N}$ Advanced Force Gauge (Mecmesin Corporation, Sterling, VA, USA) and custom grips and compressors were designed and calibrated by JA King \& Company (Whitsett, NC, USA) (Fig. 1). The compressors were designed to mimic ballpoint fingertip contact with a bottle. For each medication, the bottle was housed in the apparatus and clamps were adjusted until the ballpoint compressors were located at mid bottle length. For bottles with a rectangular instead of round shape, the thinner dimensions were chosen for compression, as this represents the method most likely to be utilized by patients when instilling drops. Starting at $0 \mathrm{~kg}$-force $(\mathrm{kgf})$ and $0 \mathrm{~mm}$ $(\mathrm{mm})$ displacement, the gauge was advanced in $0.1 \mathrm{~mm}$ increments until a drop of liquid fell from the bottle, as observed subjectively and confirmed with an automated VCD-BTD drop counter (Vernier Software and Technology, Beaverton, OR, USA) and LabQuest 2 display (Vernier Software and Technology, Beaverton, OR, USA). At a rate of approximately one drop/s, 10 drops were expressed, then the apparatus was retracted to $0 \mathrm{kgf}$. This was repeated until all drops were exhausted from the bottle.

Simultaneously, drop size and number was also estimated using the densitometric method for volume determination [19]. In twenty drop increments, the total volume of solution expressed was measured with a $0.0001 \mathrm{~g}$ analytical balance (Ohaus Corporation, Parsippany, NJ, USA). This was repeated until all drops were exhausted from the bottle. A 200 uL pipette (Zhejiang Huawei Scientific Instrument Co, LTD, Zhe Jiang, China) was used to remove four 100-uL aliquots of each bottle. The mean of the samples was divided by $0.1 \mathrm{~mL}$ to estimate the volume of each drop and each bottle by dividing the mass of each by the calculated density. For any bottles with residual liquid in the container lid, this was removed with the pipette and volume was measured separately.

Six bottles of each medication were tested. Three bottles were tested in the vertical orientation with the bottle

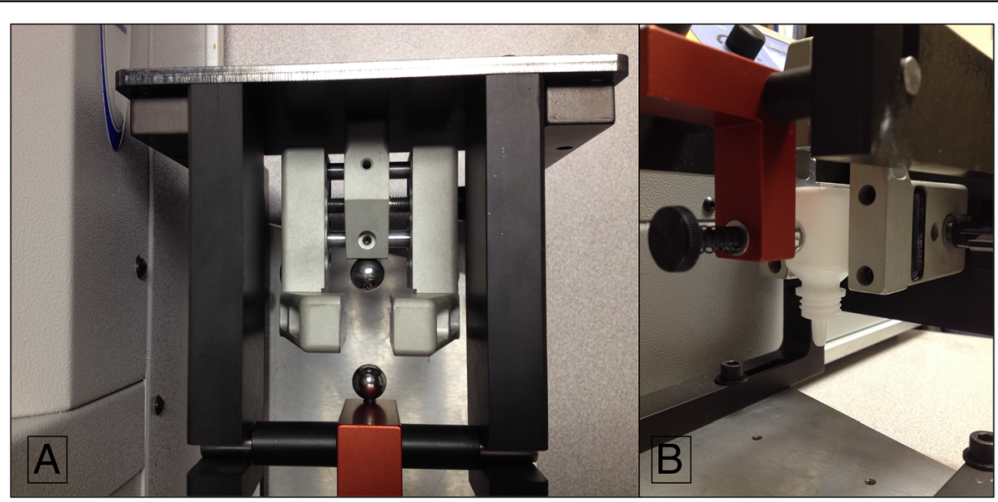

Fig. 1 Force Gauge Apparatus. A force gauge apparatus consisting of a Mecmesin M500E Motorized Tension and Compression Stand, Mecmesin 100 N Advanced Force Gauge and custom grips and compressors were designed and calibrated by JA King \& Company. a: The compressors were designed to mimic ballpoint fingertip contact with a bottle tip. b: For each medication, the bottle was housed in the apparatus and clamps were adjusted until the ballpoint compressors were located at mid bottle length. The L-shaped compression clamp was then adjusted until the force gauge sensor was centered on the crosshairs of the clamp at a 90-degree angle 
Table 1 Description of Glaucoma Medications Tested

\begin{tabular}{|c|c|c|}
\hline Medication Name & Formulation & Manufacturer \\
\hline \multicolumn{3}{|l|}{$2.5 \mathrm{ml}$} \\
\hline Travatan & travaprost $0.004 \%$ & Alcon Laboratories, Inc. Fort Worth, TX 76134 \\
\hline Travaprost & travaprost $0.004 \%$ & Par Pharmaceutical Cos. Inc. Spring Valley, NY 10977 \\
\hline Xalatan & latanoprost $0.005 \%$ & Pharmacia\&Upjohn Co, Division of Pfizer, Inc. NY, NY 10017 \\
\hline Latanoprost & latanoprost $0.005 \%$ & Akorn, Inc. Lake Forest, IL 60045 \\
\hline Lumigan & bimatoprost $0.001 \%$ & Allergan, Inc. Irvine, CA 92612 \\
\hline \multicolumn{3}{|l|}{$5 \mathrm{ml}$} \\
\hline Lumigan & bimatoprost $0.001 \%$ & Allergan, Inc. Irvine, CA 92612 \\
\hline Travaprost & travaprost $0.004 \%$ & Par Pharmaceutical Cos. Inc. Spring Valley, NY 10977 \\
\hline Travatan & travaprost $0.004 \%$ & Alcon Laboratories, Inc. Fort Worth, TX 76134 \\
\hline Alphagan P 0.1\% & brimonidine tartrate $0.1 \%$ & Allergan, Inc. Irvine, CA 92612 \\
\hline Combigan & $\begin{array}{l}\text { brimonidine tartrate } 0.2 \% \text {, } \\
\text { timolol maleate } 0.5 \%\end{array}$ & Allergan, Inc. Irvine, CA 92612 \\
\hline Timolol Pacific & timolol maleate $0.5 \%$ & Pacific Pharma, Irvine CA, 92,612 \\
\hline Timolol Hi-Tech & timolol maleate $0.5 \%$ & Hi-Tech Pharmacal Co, Inc. Amityville, NY 11701 \\
\hline Timolol Sandoz & timolol maleate $0.5 \%$ & $\begin{array}{l}\text { Alcon Laboratories, Inc. Fort Worth, TX } 76134 \text { for Sandoz Inc. } \\
\text { Pricenton, NJ } 08540\end{array}$ \\
\hline Betimol & timolol maleate $0.5 \%$ & Akorn, Inc. Lake Forest, IL 60045 for Oak Pharmaceuticals, Inc. \\
\hline Timoptic XE & timolol maleate $0.5 \%$ & $\begin{array}{l}\text { Merck Sharp \& Dohme-Chibret } 63,963 \text { Clermont-Ferrand Cedex } \\
\text { 9, France; Distributed by Valeant Ophthalmics, a division of } \\
\text { Valeant Pharmaceuticals North America LLC, } \\
\text { Bridgewater, NJ } 08807\end{array}$ \\
\hline Timoptic & timolol maleate $0.5 \%$ & $\begin{array}{l}\text { Merck Sharp \& Dohme-Chibret } 63,963 \text { Clermont-Ferrand Cedex } \\
\text { 9, France; Distributed by Valeant Ophthalmics, } \\
\text { a division of Valeant Pharmaceuticals } \\
\text { North America LLC, Bridgewater, NJ } 08807\end{array}$ \\
\hline Istalol & timolol maleate $0.5 \%$ & $\begin{array}{l}\text { Bausch\&Lomb Incorporated Tampa, FL } 33637 \text { under License } \\
\text { from Senju Pharmaceutical Co, Ltd. Osaka, Japan 541-0046 }\end{array}$ \\
\hline \multicolumn{3}{|l|}{$7.5 \mathrm{ml}$} \\
\hline Lumigan & bimatoprost $0.001 \%$ & Allergan, Inc. Irvine, CA 92612 \\
\hline \multicolumn{3}{|l|}{$8 \mathrm{ml}$} \\
\hline Simbrinza & $\begin{array}{l}\text { brinzolamide } 1 \% \text {, brimonidine } \\
\text { tartrate } 0.2 \%\end{array}$ & Alcon Laboratories, INC 6201 South Freeway, Fort Worth, TX 76134 \\
\hline \multicolumn{3}{|l|}{$10 \mathrm{ml}$} \\
\hline Cosopt & $\begin{array}{l}\text { dorzolamide HCL } 22.3 \mathrm{mg} / \mathrm{ml} \text {, } \\
\text { timolol maleate } 6.8 \mathrm{mg} / \mathrm{ml}\end{array}$ & Akorn, Inc. Lake Forest, IL 60045 \\
\hline Dorz/Tim Hi-Tech & $\begin{array}{l}\text { dorzolamide } \mathrm{HCL} 22.3 \mathrm{mg} / \mathrm{ml} \text {, } \\
\text { timolol maleate } 6.8 \mathrm{mg} / \mathrm{ml}\end{array}$ & Hi-Tech Pharmacal Co, Inc. Amityville, NY 11701 \\
\hline Dorz/Tim Bausch & $\begin{array}{l}\text { dorzolamide HCL } 22.3 \mathrm{mg} / \mathrm{ml} \text {, } \\
\text { timolol maleate } 6.8 \mathrm{mg} / \mathrm{ml}\end{array}$ & Bausch \& Lomb Incorporated Tampl, FL 33637 \\
\hline Dorz/Tim Sandoz & $\begin{array}{l}\text { dorzolamide HCL } 22.3 \mathrm{mg} / \mathrm{ml} \text {, } \\
\text { timolol maleate } 6.8 \mathrm{mg} / \mathrm{ml}\end{array}$ & $\begin{array}{l}\text { Alcon Laboratories Inc. Fort Worth Tx 76,134 for Sandoz Inc. } \\
\text { Princeton, NJ } 08540\end{array}$ \\
\hline Trusopt & dorzolamide HCL 2\% & $\begin{array}{l}\text { Merck Sharp \& Dohme Corp.,a subsidiary of Merck \& Co, Inc. } \\
\text { Whitehouse Station, NJ } 08889\end{array}$ \\
\hline Dorz Hi Tech & dorzolamide HCL 2\% & Hi-Tech Pharmacal Co, Inc. Amityville, NY 11701 \\
\hline Dorz Bausch & dorzolamide HCL 2\% & Bausch \& Lomb Incorporated Tampa, FL 33637 \\
\hline Dorz Teva & dorzolamide HCL 2\% & $\begin{array}{l}\text { Teva Pharmaceutical Ind, Ltd. Jerusalem, } 91,010 \text {, Israel for Teva } \\
\text { Pharmaceuticals USA Sellersville, PA } 18960\end{array}$ \\
\hline Dorz Sandoz & dorzolamide HCL 2\% & $\begin{array}{l}\text { Alcon Laboratires, Inc. Fort Worth, TX } 76134 \text { for Sandoz Inc. } \\
\text { Princeton, NJ } 08540\end{array}$ \\
\hline
\end{tabular}


Table 1 Description of Glaucoma Medications Tested (Continued)

\begin{tabular}{lll}
\hline Azopt & brinzolamide 1\% & Alcon Laboratories, Inc. Fort Worth, TX 76134 \\
Combigan & brimonidine tartrate 0.2\%, timolol maleate 0.5\% & Allergan, Inc. Irvine, CA 92612 \\
Alphagan P 0.15\% & brimonidine tartrate 0.15\% & Allergan, Inc. Irvine, CA 92612 \\
Alphagan P 0.1\% & brimonidine tartrate 0.1\% & Allergan, Inc. Irvine, CA 92612 \\
\hline
\end{tabular}

The medication name and volume used in the study, the formulation and manufacturer are listed

tip at 180 degrees and three bottles were tested in the near horizontal orientation with the bottle tip at 30 degrees. The vertical and horizontal orientations were the starting position for the bottle tip during each measurement, as compression of the bottle variably and slightly changed the tip position.

\section{Statistical analysis}

Mean response was compared by constructing an analysis of variance for a two way layout with factors: position (horizontal versus vertical) and bottle (all combinations of medication name and formulation). A highly significant interaction between position and bottle was obtained $(p<0.0001)$. Post hoc comparison of means was done by comparing means between positions for each bottle by using two sample t-tests. To compare different bottle designs in the same orientation, Fisher's least significant differences allowance was computed. Statistical significance was determined at the 0.01 level to minimize the Type I error rate.

\section{Results}

A total of 192 bottles from 32 bottle designs and manufacturers of medication were tested (Table 1). Further reference to medications will include brand name, manufacturer if more than one generic and bottle volume for identification. Fifteen formulations came from the same lot, sixteen came from a combination of two different lots and one came from a combination of three different lots. When comparing the mean value of variance between formulations from the same or different lots, there was no statistical difference $(p=0.62)$. Comparing mean number of drops per bottle using observed measurements versus the densitometric method to calculate number of drops in the bottle, there was no difference in the vertical ( $p=0.35$, paired t-test), but a significant difference between measurements in the horizontal ( $p=0.02$, paired t-test) position. Observed measurements via the automated drop counter were used for subsequent analysis.

The mean number and standard deviation of drops per bottle in the horizontal, vertical and summative positions of all formulations are provided in Table 2. For $2.5 \mathrm{~mL}$ bottles, the mean number of drops ranged from 75.3-101.7 and 72-102.3 in the vertical and horizontal orientations, respectively. For $5 \mathrm{~mL}$ bottles, the range was 111-209.3 and 115-189 drops in the vertical and horizontal orientations, respectively. For $10 \mathrm{~mL}$ bottles, the range was 193.7-313.3 and 234-323.7 drops in the vertical and horizontal orientations, respectively. Twenty-two of the 32 bottle designs had a significantly different mean number of drops in the vertical and horizontal positions, with 10 designs have more drops dispensed in the horizontal orientation and 12 in the vertical.

The mean bottle and drop volume are also listed in Table 2. Bottle volumes were measured with and without accounting for residual volume in the cap of the container, with less than a $2.2 \%$ difference of the overall mean in $90 \%$ of the bottles. Presented bottle volume measurements include the cap volume. For $2.5 \mathrm{~mL}$ bottles, the range was $2.37-2.69 \mathrm{~mL}$ and $2.38-2.70 \mathrm{~mL}$ in the vertical and horizontal orientations, respectively. For $5 \mathrm{~mL}$ bottles, the range was $4.72-5.93 \mathrm{~mL}$ and $4.67-5.66 \mathrm{~mL}$ in the vertical and horizontal orientations, respectively. For $10 \mathrm{~mL}$ bottles, the range was 8.93-10.2 $\mathrm{mL}$ and $8.38-9.79 \mathrm{~mL}$ in the vertical and horizontal orientations, respectively. Six of the 32 bottle designs had a significantly different mean total bottle volume in the vertical and horizontal positions, with all designs having greater volume in the vertical position. There were no significant differences between the horizontal and vertical measured drop volume for any designs.

Given the multiple different comparisons possible between bottle type, size and volume, an adjusted ratio of mean number of drops/mean bottle volume was created (Table 2), with a range from $20.9 \mathrm{drops} / \mathrm{mL}$ to 40.8 drops $/ \mathrm{mL}$ among the bottle designs and positions. Nineteen formulations had a significantly different ratio between the horizontal and vertical positions $(p<0.01)$. For comparing means between two bottle designs in the same orientation, any two means that differ by a value of 5.27 or greater are significantly different $(p<0.01)$.

\section{Discussion}

The results of this study suggest there is significant variability in the number of drops and volume per bottle of glaucoma medications, both in terms of which bottle design and manufacturer is utilized and the position the bottle is held when squeezed. For example, if a representative patient from this region is prescribed a $5 \mathrm{~mL}$ 
Table 2 Mean Number of Drops, Volume and Drop/Nolume Ratio per Glaucoma Medication Tested

\begin{tabular}{|c|c|c|c|c|c|c|c|c|c|c|c|}
\hline \multirow[t]{2}{*}{ Drop } & \multicolumn{2}{|l|}{ Mean \# Drops } & \multirow[b]{2}{*}{$p$ value } & \multicolumn{3}{|c|}{ Mean Bottle Volume } & \multicolumn{2}{|c|}{$\begin{array}{l}\text { Mean Drop } \\
\text { Volume }\end{array}$} & \multicolumn{3}{|c|}{ Mean Drops/mL } \\
\hline & vert & horz & & vert & horz & $p$ value & vert & horz & vert & horz & $p$ value \\
\hline \multicolumn{12}{|l|}{$2.5 \mathrm{ml}$} \\
\hline Travatan & $76.3 \pm 4.2$ & $102.3 \pm 1.5$ & $<0.01$ & $2.57 \pm 0.07$ & $2.53 \pm 0.04$ & & 0.032 & 0.025 & $29.66 \pm 1.35$ & $40.4 \pm 1.07$ & 0.0004 \\
\hline Travaprost & $75.3 \pm 5.1$ & $72 \pm 1$ & & $2.46 \pm 0.04$ & $2.36 \pm 0.07$ & & 0.032 & 0.032 & $30.6 \pm 2.51$ & $30.47 \pm 1.14$ & 0.9445 \\
\hline Xalatan & $101.3 \pm 0.6$ & $83.3 \pm 3.1$ & & $2.69 \pm 0.05$ & $2.70 \pm 0.05$ & & 0.027 & 0.032 & $37.68 \pm 0.73$ & $30.90 \pm 0.60$ & 0.0002 \\
\hline Latanoprost & $86.7 \pm 9.3$ & $76.7 \pm 5.0$ & & $2.37 \pm 0.26$ & $2.42 \pm 0.13$ & & 0.027 & 0.032 & $36.59 \pm 0.98$ & $31.63 \pm 0.76$ & 0.0023 \\
\hline Lumigan & $101.7 \pm 2.3$ & $81.7 \pm 4.0$ & $<0.01$ & $2.50 \pm 0.05$ & $2.38 \pm 0.08$ & & 0.024 & 0.029 & $40.61 \pm 0.18$ & $34.25 \pm 0.63$ & $<0.0001$ \\
\hline overall mean & 88.3 & 83.2 & & 2.52 & 2.48 & & 0.029 & 0.03 & & & \\
\hline overall median & 91 & 81 & & 2.53 & 2.46 & & 0.027 & 0.031 & & & \\
\hline overall ST DEV & 12.7 & 11.08 & & 0.15 & 0.15 & & 0.004 & 0.003 & & & \\
\hline \multicolumn{12}{|l|}{$5 \mathrm{ml}$} \\
\hline Lumigan & $195.6 \pm 4.2$ & $155 \pm 1$ & $<0.01$ & $4.97 \pm 0.06$ & $4.73 \pm 0.06$ & & 0.025 & 0.03 & $39.4 \pm 0.69$ & $32.75 \pm 0.22$ & $<0.001$ \\
\hline Travaprost & $150.3 \pm 6.5$ & $139.7 \pm 13.7$ & & $4.91 \pm 0.02$ & $4.78 \pm 0.24$ & & 0.032 & 0.035 & $30.62 \pm 1.42$ & $29.15 \pm 1.50$ & 0.2859 \\
\hline Travatan & $146.3 \pm 0.6$ & $189 \pm 1$ & $<0.01$ & $4.8 \pm 0.04$ & $4.78 \pm 0.07$ & & 0.033 & 0.026 & $30.49 \pm 0.82$ & $29.66 \pm 1.35$ & 0.0004 \\
\hline Alphagan P & $111 \pm 1$ & $117 \pm 2.6$ & & $4.89 \pm 0.05$ & $4.72 \pm 0.18$ & & 0.044 & 0.04 & $22.7 \pm 0.16$ & $24.82 \pm 0.78$ & 0.0102 \\
\hline Combigan & $148 \pm 2$ & $161.3 \pm 3.8$ & & $5.02 \pm 0.16$ & $4.67 \pm 0.07$ & 0.01 & 0.033 & 0.029 & $25.26 \pm 1.53$ & $34.57 \pm 0.50$ & 0.0003 \\
\hline Timolol Pacific & $123 \pm 1$ & $147.7 \pm 9.6$ & $<0.01$ & $4.88 \pm 0.04$ & $4.69 \pm 0.10$ & & 0.04 & 0.031 & $25.21 \pm 0.09$ & $25.21 \pm 0.09$ & 0.0206 \\
\hline Timolol Hi-Tech & $126.7 \pm 6.7$ & $149.3 \pm 4.0$ & $<0.01$ & $5.09 \pm 0.15$ & $5.04 \pm 0.13$ & & 0.041 & 0.034 & $24.89 \pm 0.56$ & $29.61 \pm 0.633$ & 0.0006 \\
\hline Timolol Sandoz & $161.3 \pm 3.5$ & $156.3 \pm 2.5$ & & $4.89 \pm 0.04$ & $4.84 \pm 0.08$ & & 0.03 & 0.031 & $33.02 \pm 0.92$ & $32.28 \pm 0.21$ & 0.2459 \\
\hline Betimol & $165.3 \pm 0.6$ & $160.7 \pm 1.2$ & & $5.17 \pm 0.035$ & $5.08 \pm 0.06$ & & 0.031 & 0.031 & $32.00 \pm 0.14$ & $31.63 \pm 0.56$ & 0.3282 \\
\hline Timoptic XE & $130.7 \pm 7.5$ & $115 \pm 9.8$ & 0.004 & $5.53 \pm 0.24$ & $4.9 \pm 0.24$ & & 0.042 & 0.043 & $23.71 \pm 2.41$ & $23.45 \pm 1.16$ & 0.8734 \\
\hline Timoptic & $209.3 \pm 5.7$ & $155.3 \pm 7.1$ & $<0.01$ & $5.93 \pm 0.03$ & $5.66 \pm 0.03$ & 0.0003 & 0.089 & 0.036 & $35.28 \pm 0.82$ & $27.6 \pm 1.21$ & 0.0008 \\
\hline Istalol & $154.6 \pm 2.1$ & $165.6 \pm 2.5$ & & $4.72 \pm 0.03$ & $4.74 \pm 0.09$ & & 0.03 & 0.029 & $32.77 \pm 0.22$ & $34.95 \pm 0.32$ & 0.0006 \\
\hline overall mean & 151.9 & 151 & & 5.06 & 4.89 & & 0.039 & 0.033 & & & \\
\hline overall median & 149 & 155.2 & & 4.93 & 4.78 & & 0.033 & 0.031 & & & \\
\hline overall ST DEV & 28.2 & 20.26 & & 0.34 & 0.28 & & 0.03 & 0.005 & & & \\
\hline \multicolumn{12}{|l|}{$7.5 \mathrm{ml}$} \\
\hline Lumigan & $294 \pm 2.6$ & $236 \pm 2$ & $<0.01$ & $7.21 \pm 0.06$ & $7.18 \pm 0.03$ & & 0.024 & 0.03 & $40.76 \pm 0.56$ & $32.85 \pm 0.18$ & $<0.001$ \\
\hline \multicolumn{12}{|l|}{$8 \mathrm{ml}$} \\
\hline Simbrinza & $180.7 \pm 3.1$ & $219.7 \pm 6.7$ & $<0.01$ & $7.51 \pm 0.03$ & $6.74 \pm 0.12$ & 0.0004 & 0.167 & 0.031 & $24.07 \pm 0.47$ & $32.58 \pm 1.22$ & 0.0003 \\
\hline \multicolumn{12}{|l|}{$10 \mathrm{ml}$} \\
\hline Cosopt & $301.7 \pm 39.6$ & $242 \pm 12.5$ & $<0.01$ & $10.2 \pm 0.17$ & $9.58 \pm 0.18$ & 0.01 & 0.033 & 0.039 & $29.56 \pm 3.66$ & $25.26 \pm 1.53$ & 0.1341 \\
\hline Dorz/Tim Hi-Tech & $303 \pm 1$ & $251.7 \pm 10.0$ & $<0.01$ & $9.23 \pm 0.34$ & $9.19 \pm 0.26$ & & 0.031 & 0.038 & $32.85 \pm 1.22$ & $27.39 \pm 0.39$ & 0.0018 \\
\hline Dorz/Tim Bausch & $313.3 \pm 1.5$ & $293.7 \pm 1.5$ & $<0.01$ & $9.22 \pm 0.23$ & $8.91 \pm 0.21$ & & 0.03 & 0.031 & $34.01 \pm 0.92$ & $32.96 \pm 0.65$ & 0.1804 \\
\hline Dorz/Tim Sandoz & $315 \pm 4.6$ & $271.3 \pm 5.8$ & $<0.01$ & $8.93 \pm 0.15$ & $8.39 \pm 0.29$ & & 0.115 & 0.031 & $35.27 \pm 1.09$ & $32.37 \pm 1.03$ & 0.0288 \\
\hline Trusopt & $313.3 \pm 20.0$ & $236 \pm 5.6$ & $<0.01$ & $10.18 \pm 0.20$ & $9.60 \pm 0.33$ & & 0.221 & 0.051 & $30.77 \pm 1.86$ & $24.59 \pm 0.94$ & 0.0068 \\
\hline Dorz Hi Tech & $292.7 \pm 10.3$ & $261.7 \pm 12.9$ & $<0.01$ & $9.54 \pm 0.19$ & $9.13 \pm 0.29$ & & 0.033 & 0.035 & $20.92 \pm 17.91$ & $28.70 \pm 2.21$ & 0.5313 \\
\hline Dorz Bausch & $289.7 \pm 4.2$ & $289 \pm 4.6$ & & $9.18 \pm 0.26$ & $8.78 \pm 0.15$ & & 0.032 & 0.03 & $31.55 \pm 0.61$ & $32.91 \pm 0.06$ & 0.0594 \\
\hline Dorz Teva & $282 \pm 11.5$ & $260 \pm 1$ & $<0.01$ & $9.31 \pm 0.58$ & $8.69 \pm 0.12$ & & 0.033 & 0.034 & $30.33 \pm 0.79$ & $29.91 \pm 0.31$ & 0.4423 \\
\hline Dorz Sandoz & $193.7 \pm 3.79$ & $253.7 \pm 15.3$ & $<0.01$ & $9.19 \pm 0.12$ & $8.38 \pm 0.08$ & 0.0006 & 0.332 & 0.034 & $21.06 \pm 0.16$ & $30.26 \pm 1.94$ & 0.014 \\
\hline Azopt & $254.3 \pm 2.1$ & $322 \pm 8.9$ & $<0.01$ & $9.42 \pm 0.08$ & $8.59 \pm 0.04$ & $<0.0001$ & 0.037 & 0.027 & $27.01 \pm 0.38$ & $37.5 \pm 1.08$ & $<0.001$ \\
\hline Combigan & $270.3 \pm 28.4$ & $323.7 \pm 17.8$ & $<0.01$ & $9.86 \pm 0.21$ & $9.79 \pm 0.07$ & & 0.034 & 0.03 & $27.4 \pm 2.50$ & $33.07 \pm 1.64$ & 0.0303 \\
\hline
\end{tabular}


Table 2 Mean Number of Drops, Volume and Drop/Nolume Ratio per Glaucoma Medication Tested (Continued)

\begin{tabular}{|c|c|c|c|c|c|c|c|c|c|c|}
\hline Alphagan $0.15 \%$ & $212.7 \pm 3.1$ & $234 \pm 3.6$ & $<0.01$ & $9.78 \pm 0$ & $9.53 \pm 0.09$ & 0.046 & 0.041 & $21.75 \pm 0.31$ & $24.56 \pm 0.16$ & 0.0002 \\
\hline Alphagan $0.1 \%$ & $216 \pm 4$ & $283.3 \pm 5.5$ & $<0.01$ & $9.93 \pm 0.19$ & $9.61 \pm 0.07$ & 0.046 & 0.037 & $21.75 \pm 0.11$ & $24.80 \pm 0.41$ & 0.0002 \\
\hline overall mean & 273.7 & 267.5 & & 9.54 & 9.09 & 0.079 & 0.034 & & & \\
\hline overall median & 290 & 261 & & 9.51 & 9.02 & 0.034 & 0.033 & & & \\
\hline overall ST DEV & 42.69 & 31.07 & & 0.45 & 0.51 & 0.119 & 0.005 & & & \\
\hline
\end{tabular}

The mean number of drops, bottle volume, drop volume and ratio of mean number of drops per bottle volume of three bottles tested for each medication in the vertical and horizontal positions. Medications are grouped by volume and an overall mean, median and standard deviation for all medications of similar volumes are provided. A $p$-value for medications with a significant difference in mean drop number between the horizontal and vertical position is listed, with significance determined at $p=0.01$. A ratio of mean number of drops/mean bottle volume is listed, and any two means that differ by a value of 5.27 or greater are significantly different $(p<0.01)$. Volume measurements are in milliliters $(\mathrm{mL})$. A bold value indicates a $p$ value of statistical significance

bottle of timolol $0.5 \%$, there are 5 different generic and brand bottle designs that may be dispensed. The patient could anticipate a range of 123-209 and 147-166 mean drops per bottle in the horizontal and vertical positions, respectively. If instilled twice daily, this would suggest a difference between 25.5 to 43 days of available medication depending on the manufacturer and bottle position.

This study is the first to our knowledge to present an objective, automated and reproducible method to measure the number of drops available per bottle of medication. Further, we measured countable drops instead of calculating the number of drops based on volume, which was shown to be inaccurate. Several previous studies have evaluated small samples of bottle formulations with similar, variable results. A 1994 study of patients blinded to either use of a $5 \mathrm{~mL}$ bottle of timolol maleate versus levobunolol found a $21 \%$ greater length of use of timolol (37 versus 29 days) [16]. Another study evaluated 45 versus 90 degree administration of artificial tear bottles and found a significantly greater number of drops per bottle using densitometric analysis and smaller drop volume for 4 out of 5 formulations at 45 compared to 90 degrees. The authors suggest administration at 45 degrees would result in up to $\$ 1.93$ savings per bottle compared to 90 degrees [17]. A study evaluating $2.5 \mathrm{ml}$ bottles of prostaglandin analogues held vertically, at 45 degrees and horizontally found that vertical instillation resulted in more drops per bottle for bimatoprost and latanoprost, while 45 degrees was most efficient for travaprost. Assuming 1 year of bilateral therapy at 2006 costs, the authors determined use of the most efficient instillation method would result in yearly savings of \$109-192 [18]. Lastly, a recent study found significant variability in the number of eyedrops per bottle of four regionally available formulations of latanoprost when measured by manually counting the number of drops expressed by hand, ranging from 77.6 to 88.7 drops per bottle. The authors estimated a similarly significant difference in estimated annual cost, ranging from $\$ 184$ to $\$ 1198$ per formulation [20].

Currently, there exist no federal guidelines to regulate bottle design or amount of drops available per volume of medication $[14,15]$. It has been suggested that pharmacists often use a rough guideline of $0.05 \mathrm{~mL}$ per eyedrop or 20 drops per $\mathrm{mL}$ (written personal communication, Division of Drug Information, FDA, March 27, 2015). With that in mind, there are significantly more eyedrops per bottle in this analysis than recommended, ranging from $10.4 \%$ to $45.8 \%$ more mean drops per bottle tested. This may indicate that manufacturers "overfill" the bottles to allow for a margin of error during dispensing. If true, this serves an important purpose, since it is known that many patients require more than one eyedrop per application $[9,10]$. However, this data suggests another problem has been created by this practice: significant variability in the number of doses per bottle.

Aside from bottle volume, an additional factor influence the number of drops available per bottle is drop size. We found significant variability in the estimated drop size of studied formulations, ranging from 0.024 to $0.221 \mathrm{~mL}$. The size of drop dispensed from a bottle depends on three basic elements: the design of the dropper bottle and tip, properties of the contained solution and the position of the bottle. The surface area around the bottle tip and surface tension of the solution are both manufacturer controlled factors that influence drop size. Patient manipulations such as the angle and rate drops are produced are less predictable [11]. Further, the results of the current study and others suggest the most economical bottle position varies from one design to the next [17-19]. A final potential determinant of drop size is the force required to squeeze the bottle, which unfortunately is significantly variable in both the experimental and clinical setting [21, 22]. With all of these influences, it may be difficult to design an ideal bottle for instillation. One expert suggestion has been to utilize a dropper tip with a smaller outer orifice diameter that provides consistent surface area for a smaller-volume drop to fall [11].

This study has several limitations. The experimental design was novel, and although measurements were automated, they have not been independently verified. Because the study was conducted in an objective and reproducible manner, it may not accurately reflect many of the patient related factors in dosing; it is likely that 
our patients experience even greater variability in the number of drops available per bottle. Only two bottle positions were tested and most ophthalmic containers are not intended to be delivered in a strictly horizontal position. While 192 bottles from 32 bottle designs were tested, they still represent a small sampling of all available brand and generic ophthalmic medications.

\section{Conclusion}

In summary, this study demonstrates the significant variability in drops and volume available per bottle of glaucoma medication depending on both the bottle position and manufacturer. This unregulated practice leaves prescribing physicians and pharmacists unable to accurately predict the quantity of medication to dispense. This may lead to patients running out of medication early or being left with excess and associated costs. The variability from one refill to the next could be a contributor to limited compliance. The experimental design in this study indicates an objective, reproducible method to determine drop number uniformly across different bottles and designs. It should compel further evaluation and consideration of standardization in the industry.

\section{Abbreviations}

$\mathrm{mL}$ : milliliter; mm: millimeter; $\mu \mathrm{l}$ : microliter

\section{Acknowledgments}

The authors would like to acknowledge Dr. Jayakrishna Ambati (University of Kentucky, Department of Ophthalmology \& Visual Sciences) for his insight and guidance with the manuscript preparation.

\section{Funding}

The project described was supported by the National Center for Research Resources and the National Center for Advancing Translational Sciences, National Institutes of Health, through Grant UL1TR000117. The content is solely the responsibility of the authors and does not necessarily represent the official views of the $\mathrm{NIH}$.

\section{Availability of data and materials}

The datasets generated and/or analyzed during the current study are available from the corresponding author on reasonable request.

\section{Authors' contributions}

DBM participated in all aspects of the study. JB aided in study design, acquisition of resources and review of the manuscript. RJK aided in study design, provided statistical support and analysis and review of the manuscript. All authors read and approved the final manuscript.

\section{Competing interests}

The authors declare that they have no competing interests.

\section{Consent for publication}

Not applicable.

Ethics approval and consent to participate Not applicable.

\section{Publisher's Note}

Springer Nature remains neutral with regard to jurisdictional claims in published maps and institutional affiliations.

\section{Author details}

'Department of Ophthalmology and Visual Sciences, University of Kentucky, 740 S. Limestone, Lexington, KY 40536, USA. ${ }^{2}$ Departments of Biostatistics and Statistics, University of Kentucky, Lexington, KY, USA.

Received: 11 January 2017 Accepted: 15 May 2017

Published online: 22 May 2017

References

1. Leske MC, Heijl A, Hussein M, et al. Early manifest glaucoma trial group. Factors for glaucoma progression and the effect of treatment: the early manifest glaucoma trial. Arch Ophthalmol. 2003;121(1):48-56.

2. The AGIS Investigators. The advanced glaucoma interventional study (AGIS): 7, the relationship between control of intraocular pressure and visual field deterioration. Am J Ophthalmol. 2000;130(4):429-40.

3. Gordon ME, Kass MA. Validity of standard compliance measures in glaucoma compared with an electronic eye drop monitor. In: Cramer JA, Spilker B, editors. Patient compliance in medical practice and clinical trials. New York: Raven Press; 1991. p. 163-73.

4. Kass MA, Meltzer DW, Gordon M, et al. Compliance with topical pilocarpine treatment. Am J Ophthalmol. 1986;101(5):515-23.

5. Okeke CO, Quigley HA, Jampel HD, et al. Interventions improve poor adherence with once daily glaucoma medications in electronically monitored patients. Ophthalmology. 2009;116(12):2286-93.

6. Tsai JC, McClure CA, Ramos SE, et al. Compliance barriers in glaucoma: a systematic classification. J Glaucoma. 2003:12(5):393-8.

7. Newman-Casey PA, Robin AL, Blachley T, et al. The most common barriers to glaucoma medication adherence: a cross-sectional survey. Ophthalmology. 2015;122(7):1308-16.

8. Winfield AJ, Jessiman D, Williams A, et al. A study of the causes of noncompliance by patients prescribed eyedrops. Br J Ophthalmol. 1990;74(8):477-80.

9. Stone JL, Robin AL, Novack GD, Covert DW, Cagle GD. An objective evaluation of eyedrop instillation in patients with glaucoma. Arch Ophthalmol. 2009;127(6):732-6.

10. Hennessy AL, Katz J, Covert D, Protzko C, Robin AL. Videotaped evaluation of eyedrop instillation in glaucoma patients with visual impairment or moderate to severe visual field loss. Ophthalmology. 2010;117(12):2345-52.

11. Van Santvliet L, Ludwig A. Determinants of eye drop size. Surv Ophthalmol. 2004:49(2):197-213.

12. Mishima S, Gasset A, Kylce S, Baum J. Determination of tear volume and tear flow. Inv Ophthalmol. 1966;5:264-76.

13. Moore DB, Walton C, Moeller KL, et al. Prevalence of early glaucoma eye drop bottle exhaustion and associated risk factors: a patient survey. BMC Ophthalmol. 2014;14:79.

14. Guidance for industry: container closure systems for packaging human drugs and biologics. US Department of Health and Human Services, Food and Drug Administration May 1999

15. Ophthalmic preparations and dispensers, 21 C.F.R § 200.50 (2015).

16. Meyer MA, Savitt ML. A comparison of timolol maleate and levobunolol. Length of use per 5-ml bottle. Ophthalmology. 1994;101(10):1658-61.

17. Gaynes BI, Singa RM, Schaab G, Sorokin Y. Impact of administration angle on the cost of artificial tear solutions: does bottle positioning minimize wastage? J Ocul Pharmacol Ther. 2007;23(2):196-201.

18. Fiscella R, Wilensky JT, Chiang TH, Walt JG. Efficiency of instillation methods for prostaglandin medications. J Ocul Pharmacol Ther. 2006;22(6):477-82.

19. Gaynes BI, Singa RM, Cao Y. Dosage variability of topical ocular hypotensive products: a densitometric assessment. J Glaucoma. 2009;18(2):149-52.

20. Queen JH, Feldman RM, Lee DA. Variation in number of doses, bottle volume, and calculated yearly cost of generic and branded latanoprost for glaucoma. Am J Ophthalmol. 2016;163:70-4.

21 Drew T, Wolffsohn JS. Usability of prostaglandin monotherapy eye droppers. Br J Ophthalmol 2015;(0):1-4

22 Moore DB, Hammer JD, Akhtari $R$, et al. Squeeze me if you can: variability in force requirements to extract a drop from common glaucoma bottles. $J$ Glaucoma. 2016;25:780-4. 